\title{
First results of pipe pile static load test in small laboratory scale
}

\author{
Michal Baca and Jaroslaw Rybak* \\ Wroclaw University of Science and Technology, Wyb. Wyspiańskiego 27, 50-370 Wrocław, Poland
}

\begin{abstract}
Presented laboratory testing program of tubular steel piles is a part of a bigger research program which contained static load tests in full scale and numerical simulations of conducted research. The main goal of the research is to compare static load tests with different working conditions of a shaft. The presented small scale model tests are the last part of the research. The paper contains the testing methodology description and first results of model pile axial loading. The static load tests in a small laboratory scale were conducted in a container filled with uniformly compacted medium sand (MSa). The first results of the investigation are presented in this paper, with the comparison of two pile capacities obtained for different roughness of the pile shaft (skin friction). The results are presented as load-displacement curves obtained by means of the BrinchHansen $80 \%$ method.
\end{abstract}

\section{Small scale pile investigation}

Static load test is considered the most reliable method of pile testing. However, the full scale tests are usually relatively expensive due to the high cost of anchoring piles or the kentlege system construction. Small scale pile testing may be, in some cases, a good supplement to full scale tests, especially when various factors (test data) must be considered. Despite the problems with proper modelling of real soil conditions and considering small scale effects, some aspects of pile capacity investigation can be properly evaluated also in small scale tests. The current research program is a development of the authors' previous experience with a bi-directional pile testing instrument. In common practice, model testing precedes the full scale site tests. In the actual case, model testing follows the experiments described in works [1], [2] and [3], where various aspects of tubular piles were examined, including standard, bi-directional and cyclic loading of tested pile. In the paper, the first results of model pipe piles static load tests are presented. The tests are part of a larger research program, which contains static load tests in full scale with various methods of displacement control [4] and numerical simulations of the conducted research [5], [6], [7]. The main goal of the research is to compare static load tests with different working conditions of a shaft. In the current study, various roughness values of model piles were tested in order to check the overall model pile capacity and separate

\footnotetext{
* Corresponding author: jaroslaw.rybak@pwr.edu.pl
} 
capacities of pile shaft and pile base. The test stand was constructed and kept in the unchanging laboratory conditions (temperature, humidity).

\section{Test stand description and method of result analysis}

The Test stand was built as a wooden container of $1250 \times 1500 \mathrm{~mm}$ in plane and $1500 \mathrm{~mm}$ depth (Fig. 1). The container was filled with medium sand, which was gradually compacted to obtain similar soil conditions (density index) in the whole container. The total height of the sand layer was $1200 \mathrm{~mm}$.

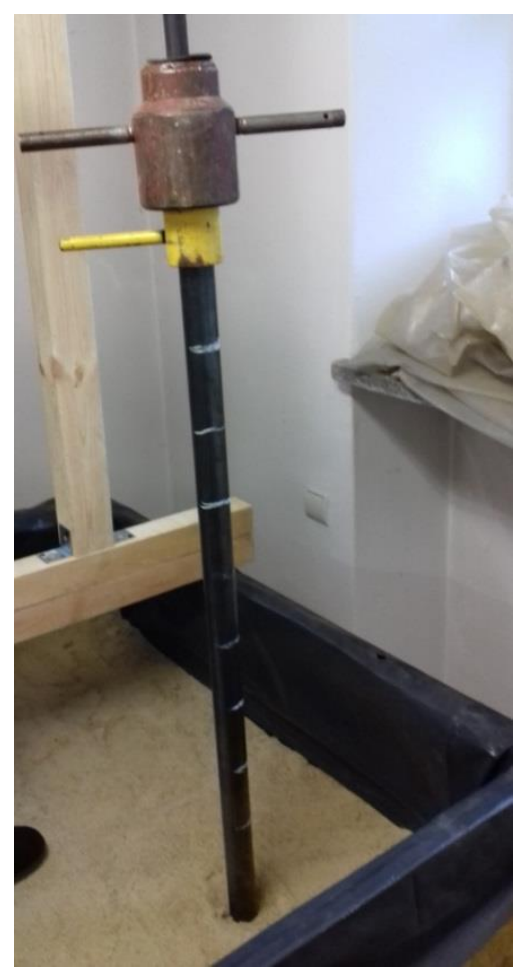

Fig. 2. Dynamic pile driving.

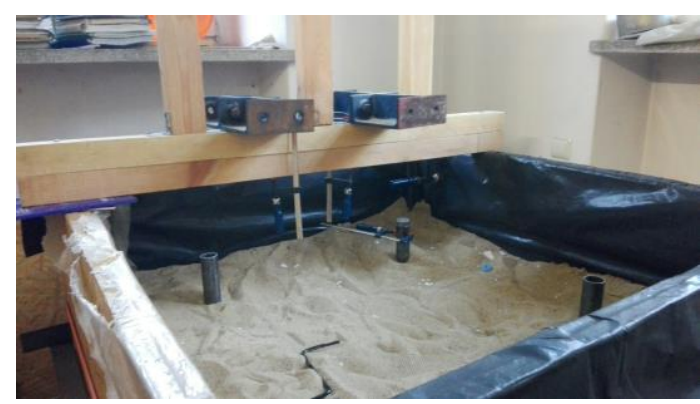

Fig. 1. Wooden container filled with medium sand.

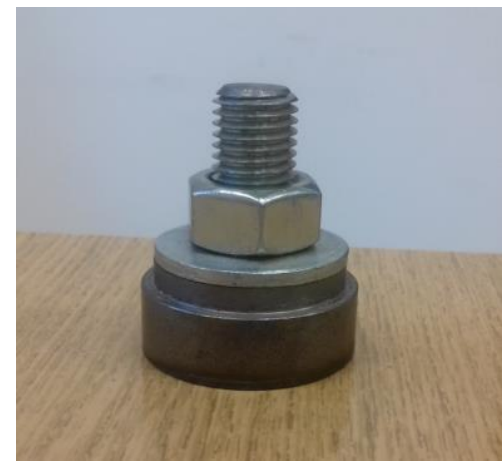

Fig. 3. Steel bottom of pile model.

The model of piles contains steel pipes with diameter $425 \mathrm{~mm}$, wall thickness $5 \mathrm{~mm}$ and length $1000 \mathrm{~mm}$. Pile models were installed (driven) in the ground by means of impact driving (Dynamic Probing Light), as presented on Fig. 2. Such procedure provides additional information about sand compaction and makes it possible to compute End of Driving pile capacity on the basis of dynamic formulae.

To avoid partial plug and to enable a separate test of pile bottom capacity, a steel toe was prepared to model the base of the pile (Fig. 3). It was placed under the pipe before the installation of each pile. Steel pipe piles were installed by means of impact driving, using the instrumentation of Dynamic Probing Light $(10 \mathrm{~kg})$. Furthermore, to provide a proper and sufficient reaction for the imposed load, a reaction system was constructed as a wooden frame (Fig. 4). For proper assessment of pile bearing capacity, the displacement control (measurement) of the pile head under applied force is required. The force was applied to a pile model by a screw jack (Fig. 5), and the value of the applied force was measured by an electronic force sensor (Fig. 5). 
The continuous recording of pile head settlement was provided by electronic displacement gauges (Fig. 5) connected to receiving unit and PC (Fig. 6).

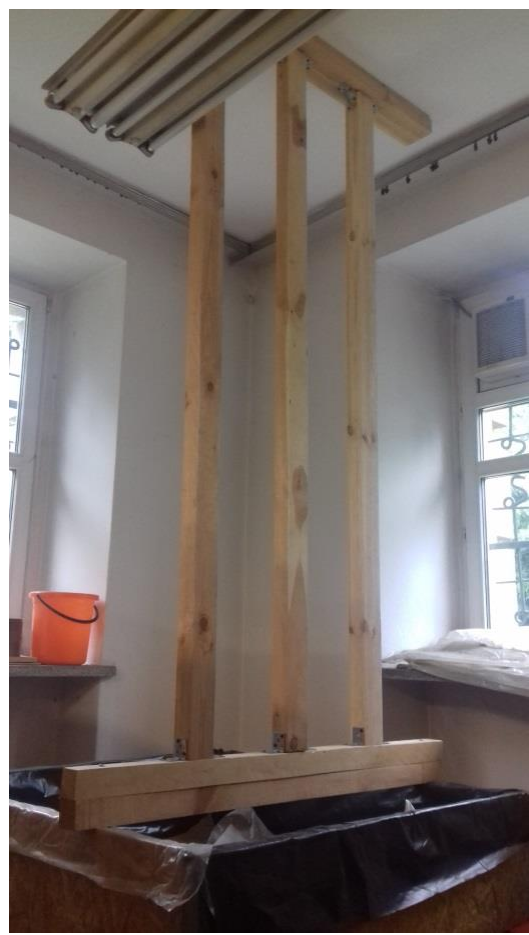

Fig. 4. Reaction frame over the pile head.

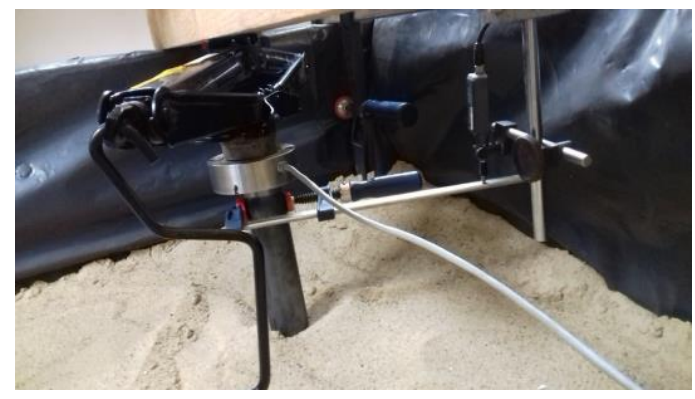

Fig. 5. Screw jack, load cell and displacement sensor.

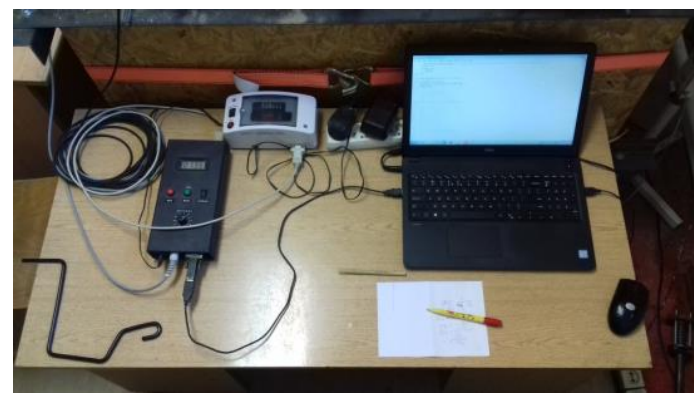

Fig. 6. Recorder unit (force, displacement).

The obtained results of load and displacement of pile head were processed by means of $80 \%$ Brinch-Hansen method [8] with respect to restrictions raised in the paper [9]. According to Brinch-Hansen [8], the ultimate capacity $Q_{u}$ is understood as such loading for which the settlement $s u$ exceeded four times the value $s$ measured after $80 \%$ of the load $Q_{u}$ has been applied. The settlement-loading relation $(s-Q)$ is then transformed into the coordinate system: $s$ - abscissa and $\sqrt{s} / Q$ - ordinates (Fig. 4). For the last points of the performed test at which the settlement reached stabilization the following linear dependence is found (by way of approximation): $\sqrt{s} / Q=A \cdot s+B$. The ultimate capacity and settlement-load relation can be then derived from formulae (1) and (2).

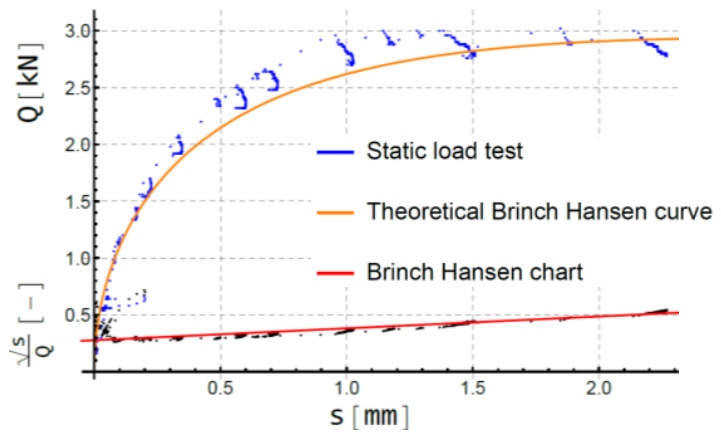

$$
\begin{aligned}
& Q_{u}=\frac{1}{2 \sqrt{A \cdot B}} \\
& Q=\frac{\sqrt{s}}{A \cdot s+B}
\end{aligned}
$$

Fig. 7. Principles of Brinch-Hansen $80 \%$ method 


\section{Static load testing results}

The obtained results of load and displacement of pile head were processed by means of $80 \%$ Brinch-Hansen method [8]. For proper assessment of pile bearing capacity, displacement control (measurement) of the pile head under the applied load is required. The load was gradually applied to a pile model by a screw jack (Fig. 5), the value of applied force was measured by an electronic force sensor (Fig. 5). Simultaneously, the ongoing displacement of pile head was measured by a displacement sensor (Fig. 5). When the displacement at a given load step had stabilized, the load was increased to next load step. The test ended when the further load increment implicated uncontrolled displacement increment. Results of static load tests for two model piles are presented in Fig. 8 and Fig. 9. The pile nr 1 (Fig. 8) had a smooth shaft, while shaft of pile nr 2 (Fig. 9) was rough.

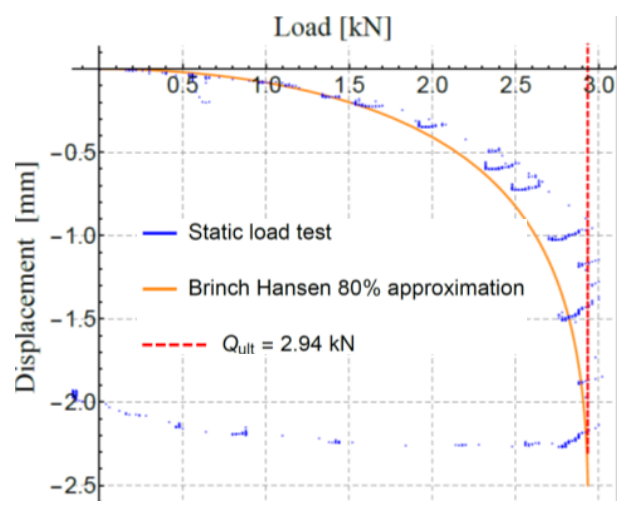

Fig. 8. Results of static load test of the model pile $\mathrm{nr} 1$ (smooth shaft)

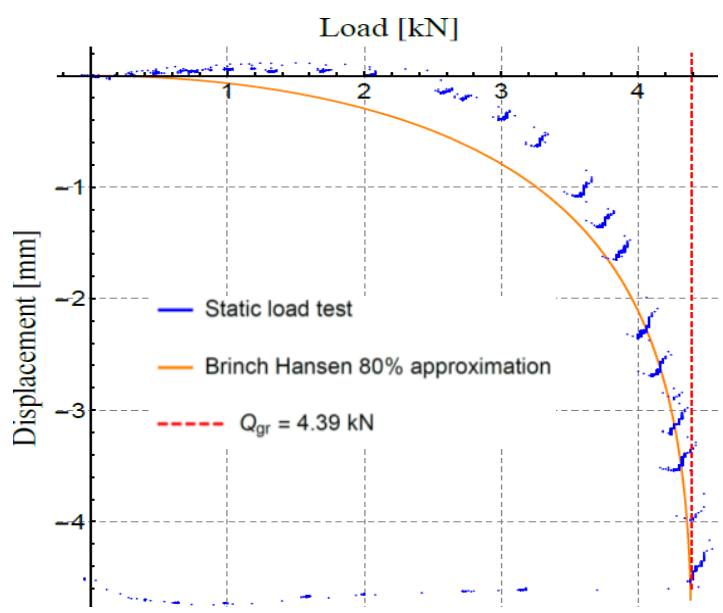

Fig. 9. Results of static load test of the model pile nr 2 (rough shaft)

\section{Summary and conclusions}

The results of the first static load tests, conducted in small scale for two model pipe piles shortly after installation, were introduced. The obtained results are promising. On loaddisplacement curves the elastic, elastoplastic and plastic parts of curve can be easily distinguished. Furthermore, the value of the ultimate bearing capacity of the pile model can also be easily indicated from a load-displacement curve. For the estimation of the shape of 
the curve and the accurate value of the bearing capacity, the Brinch Hansen $80 \%$ method was used, which provided quite accurate approximation of the obtained results. In similar soil conditions the difference in pile bearing capacity for rough (Fig. 9.) and smooth (Fig. 8.) model piles can be observed. For the model pile with rough shaft the ultimate bearing capacity was larger and was accomplished for greater values of displacement than for the model pile with a smooth shaft. As the conducted tests took place shortly after the model pile installation, it is conceived that the bearing capacity will increase in time, which will be investigated in future tests. The next part of the research will include the installation of another four piles and the same tests which were presented in the paper. The tests are also planned to be repeated at different time intervals to observe the change of pile bearing capacity in time. Furthermore, for the installed piles the static load test of only model pile base and bi-directional load tests referring to tests conducted on pipe piles in full scale are presented in $[1,2,3,4]$ Hopefully, the presented static load tests along with full scale tests and numerical simulations can be helpful for a better understanding of the pile base and shaft behaviour in different soil conditions.

The authors would like to address their gratitude to Mota-Engil Central Europe S.A. and B.U.G. GEOTECH for covering most of the cost of the presented research program.

\section{References}

1. J. Rybak, M. Baca, T. Zyrek, Practical aspects of tubular pile axial capacity testing, $15^{\text {th }}$ Int. Multidisciplinary Scientific GeoConference Surveying Geology and Mining Ecology Management, SGEM 2015, Albena, Bulgaria, 2 (1), 549-554 (2015)

2. M. Baca, J. Rybak, A.G. Tamrazyan, T. Zyrek, Pile foot capacity testing in various cases of pile shaft displacement, Int. Multidisciplinary Scientific GeoConference, SGEM 2016, Albena, Bulgaria, 1, 945-950 (2016)

3. M. Baca, Z. Muszynski, J. Rybak, T. Zyrek, A.G. Tamrazyan, Cyclic load tests of driven pile base capacity, Advances and Trends in Engineering Sciences and Technologies II - Proc. of the 2nd Int. Conf. on Eng. Sciences and Technologies, ESaT 2016, 723-728 (2017)

4. M. Baca, Z. Muszyński, J. Rybak, T. Żyrek, The application of geodetic methods for displacement control in the self-balanced pile capacity testing instrument, Advances and Trends in Engineering Sciences and Technologies - Proc. of the Int. Conf. on Engineering Sciences and Technologies, ESaT 2015, 15-20 (2016)

5. M. Drusa, J. Vlček, Numerical approach to pile load test using 3D finite element method, Komunikácie 16 (4), 94-97 (2014)

6. M. Baca, W. Brząkała, Numerical modeling of pile installation influence on surrounding soil, $17^{\text {th }}$ International Multidisciplinary Scientific GeoConference, SGEM 2017, Albena, Bulgaria, 17 (12), 619-626 (2017)

7. M. Baca, W. Brząkała, Numerical simulations of pile static load test, $X X$ Meždunarodnaâ mežvuzovskaâ naučno-praktičeskaâ konferenciâ studentov, magistrov, aspirantov i molodyh učenyh, Moscow, Russia, 1129-1131 (2017)

8. J. Brinch Hansen, Discussion, Hyperbolic Stress-Strain response, Cohesive soil., J. of Soil Mechanics and Foundation Engineering Division, ASCE, 89, 241-242, (1963)

9. J. Rybak, M. Król, Limitations and risk related to static capacity testing of piles"unfortunate case" studies, MATEC Web of Conferences, 146, 02006 (2018)

10. M. Drusa, F. Gago, J. Vlček, Contribution to Estimating Bearing Capacity of Pile in Clayey Soils, J. of Civil. and Environ. Eng., De Gruyter Open, 12 (2), 128-136, (2016) 